\title{
LA SOLUCIÓN DE CONTROVERSIAS ENTRE ESTADOS EN LOS TRATADOS DE LIBRE COMERCIO'
}

\section{LUIS GARCÍA-CORROCHANO MOYANO}

- Profesor de Derecho Internacional Público

Facultad de Derecho, UPC

\section{RESUMEN}

Los tratados de libre comercio no apuntan a crear sistemas burocráticos de integración, sino marcos legales que permitan el flujo transfronterizo de bienes y capitales. En ese sentido, al carecer de una estructura institucional permanente, requieren dotarse de sistemas de solución de controversias capaces de resolver los problemas que se presenten en el comercio entre los particulares, y también aquellos que se deriven de los actos legales y administrativos de los Estados partes, y que puedan impactar negativamente en el comercio entre ellos.

Los sistemas de solución de controversias proponen mecanismos ágiles, fiables e imparciales que permitan resolver los desacuerdos y eviten que el cumplimiento de los tratados se vea perjudicado por el surgimiento de contenciosos que paralicen su aplicación y frenen el desarrollo de los aspectos sustantivos del tratado. En ese sentido, el artículo examina y compara los mecanismos previstos en algunos tratados de libre comercio acordados a nivel regional

Palabras clave: Tratados de libre comercio, Sistemas de solución de controversias

\section{ABSTRACT}

Free trade agreements (FTAs) do not aim to create bureaucratic systems of integration, but legal frameworks that allow the cross-border flow of goods and capital. In that sense, since they lack a permanent institutional structure, they need to be equipped with dispute settlement systems capable of resolving problems arising in trade between individuals, as well as those resulting from legal and administrative acts of the participating States, and which may adversely affect trade between them. Dispute settlement systems propose agile, reliable, and impartial mechanisms for both resolving disagreements, and preventing treaty compliance from being adversely affected by emerging disputes that can paralyze their application and impede the development of the substantive aspects of the treaty. In that sense, this

1. UPC Review of Global Management, Volumen 3, Número 1, junio 2017 article examines and compares the mechanisms provided for in some regional FTAs.

Key words: Free trade agreements, Controversies solution systems

En la actualidad, los tratados de libre comercio (TLC) destacan como los instrumentos de integración y cooperación de más rápido desarrollo, especialmente los promovidos por los Estados Unidos de América con Estados de la región, pero también los que establecen otros Estados americanos entre sí y con Estados fuera de la región (principalmente europeos y de la cuenca del Pacífico). Estos instrumentos, que no son lo suficientemente homogéneos como para constituir un sistema regional de libre comercio estándar, presentan similitudes y diferencias en diversos aspectos. De entre ellas, nos proponemos abordar las referidas a la solución de controversias entre Estados ${ }^{2}$.

La intención de los TLC no es establecer nuevos sujetos de derecho internacional, tales como organizaciones interestatales, sino generar un marco jurídico de relaciones de intercambio entre los Estados parte. Este marco jurídico se inserta en el entramado de derechos y obligaciones que constituyen el derecho internacional contemporáneo, frente al cual debe tener una relación armónica, pues no puede presuponer el incumplimiento de las normas convencionales y consuetudinarias que gobiernan las relaciones entre los Estados. A tal efecto, usualmente los TLC hacen referencia a normas preexistentes que imponen obligaciones internacionales, como en el caso del Acuerdo de Marrakech — por el que se creó la Organización Mundial del Comercio (OMC) - o de los acuerdos de integración de que pueden formar parte los Estados suscriptores del TLC.

\footnotetext{
2. Los TLC usualmente establecen mecanismos de solución de controversias entre Estados, entre Estados y particulares, y entre particulares. El presente trabajo abordará únicamente la solución de controversias entre Estados.

3. "La mayor ventaja de que existan sistemas de solución de diferencias de mecanismos preferenciales es que se facilita la solución de las diferencias comerciales. Los costos de transacción entre las partes se hacen menores si se trata de vecinos o de socios comerciales que mantienen relaciones de largo plazo y saben que llegar a soluciones de manera cooperativa puede maximizar los beneficios de la relación comercial en el futuro" (Piérola Castro, Fernando, 2002, p. 177).
} 
Los capítulos de solución de controversias resultan, pues, fundamentales para prevenir y superar cualquier conflicto en la interpretación o aplicación de los TLC, ya que del objeto de esos tratados se desprende que lo esencial es la continuidad y la regularidad de su cumplimiento ${ }^{3}$. En este contexto, vamos a analizar a continuación los capítulos de solución de controversias del Tratado de Libre Comercio de América del Norte (TLCAN o, por sus siglas en inglés, NAFTA) entre Estados Unidos, Canadá y México; el TLC entre Chile y Estados Unidos, y el TLC entre el Perú y Estados Unidos.

\section{LOS TRATADOS DE LIBRE COMERCIO Y LA SOLUCIÓN PACÍFICA DE CONTROVERSIAS}

En el TLCAN (1994), la disposición de su artículo 2004 ha previsto el recurso a procedimientos de solución de controversias para la aplicación o interpretación del tratado o "en toda circunstancia en que una parte considere que una medida vigente o en proyecto de otra parte, es o podría ser incompatible con las obligaciones de este Tratado o pudiera causar anulación o menoscabo" ${ }^{\text {44 }}$ Dicha disposición se repite en el TLC Chile-Estados Unidos (2004, artículo 22.2). En el caso del TLC Perú-Estados Unidos (2009), la referencia al ámbito de aplicación es más detallada, pues incluye las controversias relativas a interpretación o aplicación, así como las medidas vigentes o en proyecto, el incumplimiento de las obligaciones derivadas del acuerdo o el beneficio razonablemente esperado bajo los capítulos Dos (Trato nacional y acceso de mercancías al mercado), Tres (Textiles y vestido), Cuatro (Reglas de origen y procedimientos de origen), Nueve (Contratación pública), Once (Comercio transfronterizo de servicios) o Dieciséis (Derechos de propiedad intelectual) que sea anulado o menoscabado por una medida de otra parte, siempre que en los casos de los capítulos Once y Dieciséis la medida no sea objeto de una excepción autorizada por el TLC (artículo 22.2.1). Como el TLC estuvo previsto inicialmente para incorporar a tres Estados de la Comunidad Andina (Perú, Colombia y Ecuador), el artículo contiene una disposición que excluye las disputas entre miembros de la Comunidad Andina del ámbito de aplicación de lo previsto en el TLC (artículo 22.2.2).

En el caso del TLCAN, su artículo 2001 estableció la Comisión de Libre Comercio, a la que facultó para "resolver las controversias que pudiesen surgir respecto a su interpretación o aplicación" (artículo 2001.2.c). Esta disposición se encuentra también en el TLC Perú-Estados Unidos (artículo 20.1). Al ser la Comisión de Libre Comercio una entidad intergubernamental, sus funciones frente a una controversia se limitarían a facilitar la negociación o el trato directo entre los Estados parte, puesto que ella

4. "Para que un sistema de comercio [...] funcione adecuadamente y sin fricciones, no basta con que exista una normativa aceptada por todos. Las normas tienen que complementarse con otras reglas que confieran a los países el derecho a obtener una reparación cuando se produzcan infracciones y que regulen la solución de controversias y sus diferencias" (Centro de Comercio Internacional UNCTAD/OMC y Commonwealth Secretariat, 1996, p. 44). reúne a representantes de los Gobiernos. Por lo tanto, una vez agotada esta instancia, se procederá a iniciar los otros procedimientos previstos por los diversos TLC como medio de solución de controversias. El artículo 2003 del TLCAN, el artículo 22.1 del TLC Chile-Estados Unidos y el artículo 21.1 del TLC Perú-Estados Unidos establecen la obligación de las partes a procurar un acuerdo sobre la interpretación y la aplicación del tratado, y a realizar "todos los esfuerzos, mediante cooperación, consultas u otros medios, para alcanzar una solución mutuamente satisfactoria".

\section{LAS CONSULTAS}

Los TLC bajo análisis tienen previsto un mecanismo de consultas (que guarda ciertas similitudes en su definición) respecto de alguna medida vigente o en proyecto o de cualquier asunto que se considere que pueda afectar el funcionamiento del tratado. Este mecanismo se pone en marcha con el requerimiento por escrito a la otra parte (u otras), con explicación de las razones de la solicitud. Así, la solicitud de consulta se deberá entregar a la sección nacional del Secretariado y a las otras partes, sin especificar cómo debe ser fundamentado el reclamo, mientras que en el TLC Chile-Estados Unidos y en el TLC Perú-Estados Unidos se entiende que las solicitudes se envían a la parte requerida. En estos casos, el solicitante deberá explicar las razones de la solicitud, identificar la medida o proyecto objeto de la consulta e indicar "los fundamentos jurídicos de la reclamación”. (Artículo 21.4.2)

Al ser cualquier norma o medida (ley, reglamento o acto de la administración pública) un producto híbrido que combina una dosis de decisión política y una naturaleza jurídica que determina su contenido y alcances o efectos, parece más adecuada la formulación de los últimos TLC, que prevén que toda reclamación deba expresar sus fundamentos jurídicos, pues la motivación política de la normas o medidas no resulta justiciable, al no poder ser analizada por separado. En todo caso, si las normas o medidas surten efectos políticos, lo hacen en tanto presentan efectos jurídicos, que sí pueden ser medidos o previstos por la relación que guarden dichas normas o medidas con las obligaciones que se derivan del tratado para cada Estado parte.

Las denominadas consultas en los TLC son las negociaciones o el trato directo entre las partes, que no se valen de mediadores, tienen libertad de forma y, salvo mínimas especificaciones, carecen de un procedimiento establecido o de plazos determinados. El TLC PerúEstados Unidos dispone que, "si una Parte solicita dichas consultas, la otra Parte responderá prontamente a la solicitud de consultas y entablará consultas de buena fe" (artículo 21.4.1), en concordancia con las disposiciones de la Convención de Viena sobre el Derecho de los Tratados de 1969, que establecen que todo tratado debe ser cumplido de buena fe (artículo 26: Pacta sunt servanda), lo que se hace extensivo a todo lo referente al cumplimiento y a la ejecución del tratado, incluso las eventuales controversias sobre la interpretación o la aplicación del mismo. Por su parte, el TLCAN y el TLC Chile-Estados Unidos determinan que, a través de las consultas, las partes harán lo posible para encontrar una solución mutuamente satisfactoria ${ }^{5}$. 
Se entiende que se tratará de una solución negociada, no de un procedimiento jurisdiccional. En el TLCAN y el TLC Perú-Estados Unidos existe la posibilidad de que una tercera parte intervenga en el procedimiento de consulta cuando tenga "interés sustancial" o "interés comercial sustancial" en el asunto, considerando el carácter plurilateral de dichos instrumentos ${ }^{6}$.

Los TLC, entre las especificaciones que configuran el proceso de consultas, establecen la obligación de las partes de aportar información suficiente, en una cantidad que permita el examen de la medida vigente o en proyecto, y estipulan que la información confidencial está sujeta al mismo trato que le otorgó la parte que la haya proporcionado. En las consultas se podrá solicitar a una parte que ponga a disposición "personal de agencias gubernamentales" (TLC Perú-Estados Unidos, artículo 21.4.6) o "funcionarios de organismos de gobierno" (TLC Chile-Estados Unidos, artículo 22.4.5) o de entidades reguladoras que tengan "conocimiento del asunto objeto de las consultas" (TLC Perú-Estados Unidos, artículo 21.4.6) o "conocimiento especializado en el asunto que es materia de las consultas" (TLC Chile-Estados Unidos, artículo 22.4.5). En el TLC Perú-Estados Unidos se determina que las consultas pueden realizarse "de manera presencial o por cualquier medio tecnológico disponible para las partes", y que, en principio, la consulta deberá desarrollarse "en la capital de la Parte consultada, a menos que se acuerde algo distinto" (artículo 21.4.4). En los otros dos tratados no se precisan ni los medios ni el lugar para el desarrollo de las consultas.

\section{ACTUACIÓN DE LA COMISIÓN DE LIBRE COMERCIO}

El procedimiento de consultas está sujeto a ciertos plazos respecto de su inicio o realización, vencidos los cuales, sin haberse logrado resolver el asunto, las partes podrán solicitar que se reúna la Comisión de Libre Comercio, la cual, en todos los casos, deberá hacerlo dentro de los siguientes diez días de la entrega de la solicitud, y abocarse sin demora a la solución de la controversia. La comisión está facultada para convocar asesores técnicos o crear los grupos de trabajo o de expertos que considere necesarios, y para recurrir a los buenos oficios, la mediación, la conciliación u otros mecanismos de solución de controversias, o formular recomendaciones

5. “5. Mediante las consultas previstas en este artículo o conforme a cualesquiera otras disposiciones consultivas del Tratado, las Partes consultantes harán todo lo posible por alcanzar una solución mutuamente satisfactoria de cualquier asunto. TLC Chile-Estados Unidos, artículo 22.4: Consulta. 4. Las Partes realizarán todos los esfuerzos para alcanzar una solución mutuamente satisfactoria respecto de cualquier asunto, a través de consultas de conformidad a este artículo o a otras disposiciones relativas a consultas de este Tratado" (TLCAN artículo 2006, Consultas).

6. Como se sabe, el TLCAN esta integrado por México, Estados Unidos y Canadá. En el caso del TLC Perú-Estados Unidos, formaron parte de las negociaciones iniciales, aunque actualmente se encuentran rezagados en las negociaciones otros dos Estados de la Comunidad Andina: Colombia y Ecuador. que puedan "ayudar a las partes a alcanzar una solución mutuamente satisfactoria" (TLCAN, artículo 2007.5; TLC Chile-Estados Unidos, artículo 22.5.4; TLC Perú-Estados Unidos, artículo 21.5.3.). El encargo dado a la Comisión de Libre Comercio es sumamente amplio, pues pone en sus manos las herramientas conocidas como medios diplomáticos de solución de controversias (buenos oficios, mediación, conciliación) e incluso le otorga libertad para recurrir a otros mecanismos del mismo tipo, como la posibilidad de convocar asesores o grupos de expertos técnicos, cuya función será determinar de manera objetiva los hechos y, en función de ello, proponer las alternativas de solución a la controversia.

Como característica principal de los medios diplomáticos tenemos su carácter no vinculante; es decir, carecen de efecto obligatorio, y por lo tanto su cumplimiento depende de la buena fe de las partes, aunque los TLC han previsto medidas de sanción para el incumplimiento. La solución que se obtiene al emplear estos medios es una de compromiso, no de derecho ${ }^{7}$. Así, una vez culminada la etapa de las consultas sin haberse llegado a una solución, el recurso a la Comisión de Libre Comercio abrirá un abanico de posibles medios de solución, de carácter más institucional. Aunque el tratado no lo señale de manera expresa, una vez que refiere a los medios de solución pacífica de controversias que el derecho internacional público admite y define, y salvo disposición distinta del mismo tratado, los mecanismos de solución de controversias que se empleen estarán regidos por el derecho internacional público para todo lo que no esté previsto en el tratado o sea acordado por las partes.

Si bien es la Comisión de Libre Comercio la llamada a solucionar las controversias y la facultada para el uso de diversos medios, nada en el texto de los tratados hace suponer que tal función necesariamente deba ser cumplida por ella, que no sea delegable o que no pudiera ser diferida a un tercero. Tampoco se excluye la posible concurrencia de otros tratados sobre solución pacífica o la participación de mecanismos preexistentes (e. g., listas de mediadores o de conciliadores) que puedan concurrir con las disposiciones del tratado. Cabe destacar que el empleo de los medios diplomáticos permite elaborar propuestas que combinen elementos políticos y jurídicos, hasta alcanzarse un acuerdo entre las partes.

\section{EL ARBITRAJE}

Los TLC también han considerado el arbitraje como medio de solución de controversias, guardando la nomenclatura de "panel arbitral" que utiliza actualmente la OMC, en lugar de la más tradicional de "tribunal arbitral", lo que además

7. "Los medios diplomáticos de solución de controversias se distinguen de los medios jurisdiccionales en el hecho de que los primeros tienden exclusivamente a facilitar el acuerdo entre las partes; en consecuencia, no tienen carácter vinculante y, dado que al utilizarlos no se tiene en cuenta los aspectos jurídicos de la controversia, su objetivo principal no es determinar quién tiene y quién no tiene la razón, sino llegar a un compromiso entre posiciones opuestas" (Novak Talavera y García-Corrochano Moyano, 2005, p. 99). 
implica cierta variación respecto de la noción de arbitraje del derecho internacional público, como veremos más adelante. El arbitraje dentro de los TLC está previsto como instancia posterior a la etapa de consultas y a la reunión de la Comisión de Libre Comercio; es decir, se iniciará ante el agotamiento de las negociaciones y de los medios diplomáticos de solución de controversias, o vencido un plazo (previsto y estipulado en el tratado) sin que se haya reunido la comisión o se haya logrado la solución del asunto. No se podrá recurrir al arbitraje para "revisar una medida en proyecto" (TLC Perú-Estados Unidos, artículo 21.6.6; TLC Chile-Estados Unidos, artículo 22.6.3), pues evidentemente el recurso a un mecanismo jurisdiccional como el arbitraje solo puede darse para resolver una controversia existente "susceptible de ser objeto de una decisión basada en el derecho internacional"8.

El procedimiento se inicia cuando la parte solicitante entrega a la otra parte la solicitud para establecer el panel o grupo arbitral, en la que se debe identificar la medida o el asunto objeto de la reclamación. Según los textos, variará la manera de fundamentar la solicitud, pues en uno se pide "identificar los fundamentos jurídicos de la reclamación" (TLC Perú-Estados Unidos, artículo 21.6.1.e) y en otro "indicar las disposiciones del Tratado que considere pertinentes" (TLC Chile-Estados Unidos, artículo 22.6.1.d). El panel o grupo arbitral se deberá establecer a la entrega de la solicitud. Solo en el caso del TLCAN se estipula que corresponde a la comisión establecer el panel arbitral (artículo 2008.2). En los casos en que el TLC involucre a más de dos Estados, la solicitud se deberá entregar a todos los otros Estados, para permitir la intervención de aquellos que consideren "tener interés sustancial en el asunto" (TLC Perú-Estados Unidos, artículo 21.6.3).

El TLC Perú-Estados Unidos contiene disposiciones (artículos 21.6.3 y 21.6.4) destinadas a limitar el derecho de intervención en un asunto por razón de oportunidad. Así, cuando una parte ha sido notificada del inicio de un procedimiento arbitral, si tiene en el asunto un "interés sustancial", debe solicitar su intervención en el plazo perentorio de siete días luego de que la parte solicitante haya pedido la conformación del panel arbitral. En caso de que decidiera no intervenir en el asunto, deberá abstenerse de iniciar o continuar un procedimiento de solución de controversias de conformidad con ese tratado, o bajo cualquier otro TLC del que forme parte conjuntamente con el demandado, o a través de los mecanismos de la OMC, alegando causales "sustancialmente equivalentes", salvo que medie un "cambio significativo en las circunstancias económicas o comerciales". Similares disposiciones se encuentran en el artículo 2008.4 del TLCAN. En este caso, se restringe el derecho de acción para limitarlo al empleo del TLC para un asunto ya iniciado, de modo que se excluya la posibilidad de emplear otro foro de manera simultánea para discutir el mismo asunto, e incluso de debatirlo posteriormente, salvo el indicado cambio significativo en las circunstancias económicas o comerciales. La intención evidente de

8. Asunto de la reclamación por daños causados a súbditos británicos en la zona española de Marruecos. Laudo del profesor Max Huber, árbitro único, 27 de abril de 1924. R.S.A., volumen II, p. 632. tal disposición no es limitar los posibles recursos de solución de controversias, sino que el mismo asunto sea llevado a foros diversos y pudiera producir resultados discordantes o contradictorios respecto de la aplicación de las disposiciones del TLC, pues, al no existir instancia de revisión o apelación, una circunstancia de este tipo llevaría a un impasse en la aplicación del tratado.

El sistema seguido por los TLC es el de establecer una lista de árbitros o panelistas designados por las partes y elegidos por consenso (TLCAN, TLC Perú-Estados Unidos) o por mutuo acuerdo (TLC Chile-Estados Unidos). Aunque el número varía (hasta 30 en el TLCAN, al menos 20 en el TLC Chile-Estados Unidos y hasta cinco por cada parte en el TLC Perú-Estados Unidos), es regla común que la mayoría de los designados pueda ser de la nación de la parte que designa y que una minoría sea extranjera. Las listas tendrán una vigencia mínima de tres años y seguirán en vigor hasta que se defina una nueva lista. Los árbitros o panelistas pueden ser reelectos (TLCAN, artículo 2009.1; TLC Chile-Estados Unidos, artículo 22.7.1; TLC PerúEstados Unidos, artículo 21.7.1).

El tratado usualmente determina las calificaciones de los panelistas o árbitros: tener conocimientos especializados o experiencia en derecho, en comercio internacional, en otros asuntos del tratado o en solución de controversias derivadas de acuerdos comerciales internacionales; ser elegidos en función de su objetividad, imparcialidad, confiabilidad y buen juicio; ser independientes, no estar vinculados con las partes ni recibir instrucciones de las mismas; y cumplir con un código de conducta establecido (TLCAN, artículo 2009.2; TLC Chile-Estados Unidos, artículo 22.7.2; TLC Perú-Estados Unidos, artículo 21.8.1).

Los TLC han previsto una serie de reglas para la conformación del panel o grupo arbitral y la designación de su presidente, de manera que las partes no puedan con su inacción frustrar el procedimiento. Si una de las partes nombra un árbitro fuera de la lista, la otra podrá recusarlo sin expresión de causa (TLC Chile-Estados Unidos, artículo 22.9.2); si se considera que un árbitro designado ha violado el código de conducta, las partes entablarán consulta y, de acordarlo, el árbitro será removido y reemplazado de acuerdo con lo previsto (TLC Perú-Estados Unidos, artículo 21.9.2; TLC Chile-Estados Unidos, artículo 22.9.3).

La reglas modelo de procedimiento arbitral deberán ser determinadas por la Comisión de Libre Comercio a la entrada en vigor del TLC, pero observando ciertas garantías básicas para el desarrollo del proceso: el derecho a tener por lo menos una audiencia pública, el de presentar alegatos y réplicas por escrito, la posibilidad de que entidades no gubernamentales participen en calidad de amicus curiae, la protección de la información confidencial, el libre empleo de las lenguas oficiales (español e inglés) y la facultad de modificar las reglas modelo de procedimiento, sea por la comisión (TLC Chile-Estados Unidos, artículo 22.10.3) o por las partes (TLC Chile-Estados Unidos, artículo 22.10.2; TLC Perú-Estados Unidos, artículo 21.10.3). Sin embargo, las partes también pueden acordar fórmulas distintas, ya sea estableciendo diferentes reglas de procedimiento o facultando al grupo o panel arbitral a variar dichas reglas o a incorporar otras adicionales. Al respecto, cabe destacar que ninguna disposición de los 
TLC se entiende en menoscabo de la facultad implícita de todo tribunal arbitral, de acuerdo con el derecho internacional público vigente, de ser juez de su propia competencia ${ }^{9}$ y de poder proveer lo necesario para cumplir su misión, lo que implica poder incorporar las reglas que sean necesarias y suficientes para llevar a cabo el arbitraje.

Se entiende que la competencia del panel o grupo está dada por lo que solicitan las partes, y eso marca el límite de su capacidad para pronunciarse sobre un asunto. Los TLC establecen que el panel o grupo deberá examinar la solicitud "a la luz de las disposiciones del tratado" y "emitir conclusiones, determinaciones y recomendaciones [...] y presentar informes escritos" según los artículos a que hace referencia cada tratado (TLC Chile-Estados Unidos, artículo 22.10.4; TLC Perú-Estados Unidos, artículo 21.10.4). Las partes deberán indicar en su solicitud si han identificado que una medida ha sido causa de anulación o menoscabo de beneficios y si desean que el panel o grupo formule conclusiones sobre los efectos comerciales adversos que hayan ocasionado el incumplimiento de las obligaciones contractuales o las medidas incompatibles con dichas obligaciones (TLC Perú-Estados Unidos, artículos 21.10.5 y 21.10.6; TLC Chile-Estados Unidos, artículo 22.10.5 y 22.10.6)

El arbitraje, según las disposiciones de los TLC, se desarrolla en etapas sucesivas, pues el panel o grupo arbitral, que al considerar el asunto ha de basarse en el tratado y en lo solicitado por las partes, deberá presentar a ellas un informe inicial o preliminar y luego un informe final.

El primero se entregará dentro de los 120 días de constituido, y contendrá las conclusiones de hecho y la determinación respecto del eventual incumplimiento del tratado en que hayan incurrido las partes, además de sus recomendaciones para la solución de la controversia, en caso de que las partes lo hayan solicitado. Los árbitros pueden presentar opiniones individuales si no han llegado a una decisión unánime en alguna cuestión. Las partes podrán hacer observaciones o solicitar aclaraciones sobre el informe preliminar, que deberán ser consideradas y respondidas por el panel o grupo, que, en función de ellas, podrá reconsiderar su informe (TLC Perú-Estados Unidos, artículo 21.13; TLC Chile-Estados Unidos, artículo 22.12).

El informe final del panel o grupo arbitral deberá presentarse, salvo que las partes lo decidan de otro modo, 30 días después de la entrega del informe inicial, y puede contener opiniones individuales en aquellos puntos sobre los que no hubo acuerdo. Sin embargo, en ninguno de los dos informes se podrá revelar la identidad de quienes han votado con la mayoría o en minoría. Recién en esta

9. “El principio de la facultad del tribunal para juzgar su propia competencia terminaba con la idea según la cual los árbitros no son más que mandatarios de las partes en controversia y no podían exceder las funciones que estas les conferían; de esta forma, se limitaba la capacidad para juzgar de manera independiente. Sin embargo, aun cuando le corresponde juzgar su propia competencia, no es el árbitro o el tribunal quien la establece, sino el tratado que le da origen y que se funda en la voluntad de las partes" (Novak Talavera y García-Corrochano Moyano, 2005, p. 118). disposición sobre la reserva respecto del voto se hace mención a una opinión en mayoría, pues las disposiciones que hacen referencia a las opiniones individuales dejan un margen de ambigüedad respecto de si es necesario que el panel o grupo llegue a un acuerdo en todos los puntos y lo haga por mayoría. Ello, dado que solo existen referencias a la ausencia de unanimidad, mas no a otra posible conformación de los informes (TLC Perú-Estados Unidos, artículo 21.14; TLC Chile-Estados Unidos, artículo 22.13).

Llegados a este punto, es necesario precisar que la forma en que los TLC entienden el arbitraje es más próxima al diseño que de tal institución elaboró primero el GATT y luego la OMC, y no al diseño que tradicionalmente se ha venido empleando desde las últimas décadas del siglo xIX y que aún hoy se utiliza en gran medida en las controversias sobre inversiones que se resuelven en distintos foros ${ }^{10}$. Debe enfatizarse que esta proximidad no se da solo por una cuestión de nomenclatura, sino fundamentalmente de estructura y procedimientos, como puede apreciarse en aspectos sustantivos tales como la presentación de informes en lugar de laudos y la ausencia de obligatoriedad de tales informes que contienen determinaciones y recomendaciones, mas no resuelven de manera definitiva la controversia, sino que dejan en manos de las partes acordar la solución final al diferendo ${ }^{11}$.

\section{CUMPLIMIENTO Y EJECUCIÓN}

El informe final servirá a las partes para acordar el fin de la controversia siguiendo las determinaciones y recomendaciones de dicho documento, procurando, de ser posible, realizar lo necesario para dejar sin efecto el incumplimiento de obligaciones establecidas por el tratado, o las medidas que hayan causado anulación o menoscabo de los beneficios esperados (TLC Perú-Estados Unidos, artículo 21.15; TLC Chile-Estados Unidos, artículo 22.14). Las medidas que se puedan establecer en el informe final (tales como compensaciones, pago de contribuciones dinerarias o suspensión de beneficios) tienen un carácter accesorio, pues no constituyen propiamente una solución a la controversia, sino un resarcimiento por los daños causados o las expectativas no cubiertas. La solución en sí se da con la eliminación de los actos o medidas que ocasionan incumplimiento del acuerdo o causan anulación

10. Pueden verse al respecto las Reglas de Procedimiento de la Corte Permanente de Arbitraje (CPA, La Haya) del Centro Internacional para Arreglo de Disputas sobre Inversiones (CIADI, Washington) o de la Cámara de Comercio Internacional (ICC, París)

11. Sobre la obligatoriedad del laudo arbitral, ver Diez de Velasco, 2003, p. 824; Novak Talavera y García-Corrochano Moyano, 2005, pp. 123-124; y Rodríguez Carrión, 2006, p. 515. Sobre el valor jurídico del informe de un panel en la OMC, ver Diez de Velasco, 2003, p. 674: “El informe del panel no es, ciertamente, equiparable a un laudo Arbitral o una sentencia, entre otras razones porque su objetivo no es solucionar directamente la controversia y, en cualquier caso, carece de valor obligatorio per se. No obstante su valor indirecto es más que considerable. Destinado el informe a convencer y persuadir al O.S.D., órgano de naturaleza claramente política, de la decisión que debe adoptar, goza de una tendencia favorable a su obligatoriedad". 
o menoscabo de un beneficio razonablemente esperado por la parte reclamante.

El incumplimiento de la compensación o solución acordada faculta a la parte reclamante a notificar su intención de suspender la aplicación de beneficios de efecto equivalente respecto de la parte demandada (TLC Perú-Estados Unidos, artículo 21.16; TLC Chile-Estados Unidos, artículo 22.15). No obstante, dicha suspensión puede ser recurrida ante un panel o grupo arbitral en caso de que se le considere excesiva. La suspensión de aplicación de beneficios solo deberá aplicarse en la medida en que el panel lo determine en un procedimiento previsto por el tratado ${ }^{12}$. Cuando la parte demandada procede a eliminar la medida o el acto que causó anulación o menoscabo, puede poner este hecho en conocimiento del panel o grupo arbitral. Este, luego de examinar el asunto, emitirá un informe para que la parte reclamante restablezca los beneficios que hubiere suspendido o cese el requerimiento de pago de contribuciones que hayan sido impuestas como sanción (TLC Perú-Estados Unidos, artículo 21.18; TLC Chile-Estados Unidos, artículo 22.17).

\section{ELECCIÓN DEL FORO}

Usualmente conocida bajo la expresión forum shopping, la elección del foro para resolver una controversia es siempre una potestad de las partes que los tratados reconocen. Los mecanismos que diseña un tratado complejo, como en el caso de los TLC, son siempre alternativos a los demás mecanismos existentes a los cuales las partes pueden acceder. El caso más notable en el comercio internacional lo constituye el mecanismo de solución de controversias previsto por la OMC. En todo caso, dicha enumeración no es limitativa, pues la elección del foro en realidad depende únicamente de dos factores: que las partes hayan acordado previamente un foro al cual recurrir en caso de controversia y que ellas mismas decidan emplear ese foro.

Por lo tanto, los TLC han previsto que las partes podrán recurrir al foro establecido por el tratado o por otro TLC al que ambas partes pertenezcan, o al establecido en el Acuerdo sobre la OMC (TLCAN, artículo 2005.1; TLC ChileEstados Unidos, artículo 22.3.1; TLC Perú-Estados Unidos, artículo 21.3.1). Se debe considerar que la elección de un foro implicará, en principio, la exclusión de los otros; es decir, no se deberá iniciar una acción arbitral paralela o con posterioridad al inicio de una demanda por idéntico motivo acogiéndose a los mecanismos previstos en otro tratado (TLCAN, artículo 2005.6; TLC Chile-Estados Unidos, artículo 22.3.2; TLC Perú-Estados Unidos, artículo 21.3.2). Esta disposición tiene como finalidad evitar que se resuelva de manera diferente sobre un mismo asunto, lo que llevaría a una situación de inaplicabilidad de las disposiciones del tratado en tanto las partes en

12. "Estas medidas encuentran su fundamento en la teoría general de las contramedidas, la cual permite al sujeto afectado por el hecho ilícito internacional de otro sujeto la utilización de medios perjudiciales para el infractor con el objetivo de restaurar el respeto por el Derecho" (Montaña Mora, 1997, p. 144) controversia aleguen tener ambas la razón y el derecho, premunidas de los laudos que las favorecen.

En cualquier caso, las partes deben, al elegir el foro para solucionar la controversia, ponderar de manera adecuada las ventajas y los riesgos que conlleva tratar la diferencia en una instancia con participación restringida de actores, como son por definición los TLC, o ventilar su controversia en un medio abierto en el que pueden participar todos los que posean un interés sustancial y similar, lo que puede dificultar o dilatar el logro de una solución ${ }^{13}$.

También debe tomarse en cuenta el interés de las partes por lograr una pronta solución a la controversia, pues, además del número de partes que intervienen, los procedimientos de cada foro tienen mecanismos y plazos que deben ser respetados en lo que se refiere a obtener una solución o a facultar la adopción de alguna medida para la parte reclamante. Otro punto que se debe considerar es en qué medida los aspectos jurídicos son predominantes en la controversia o tienen mayor relevancia para la parte reclamante. En esos casos, los mecanismos previstos en los TLC hacen mayor énfasis en proteger los intereses comerciales de las partes, visto el carácter sumario y expeditivo de los procedimientos previstos, mientras que, por ejemplo, el mecanismo de la OMC posee una doble instancia, lo que garantiza la revisión de las decisiones y otorga unidad y consistencia al empleo de las reglas de derecho ${ }^{14}$.

En lo que se refiere a mayor garantía de resoluciones sujetas a derecho, el mecanismo de solución de diferencias de la OMC otorga mayor seguridad jurídica debido a su doble instancia cuasi-judicial. En efecto, el papel fundamental que cumple el Órgano de Apelación asegurando la coherencia en el manejo de los conceptos jurídicos y las reglas de la OMC no tiene par en el contexto del TLCAN ni de otros acuerdos comerciales (Piérola Castro, 2002, p. 203).

13. "Otro aspecto significativo es el número de terceras partes que pueden participar en cada uno de los procedimientos. En el caso del TLCAN, solo existe la posibilidad de que el Estado restante participe en la diferencia. Sin embargo, en el marco de la OMC todos aquellos miembros que posean un interés comercial sustancial pueden solicitar su participación. Este factor impone evidentemente mayor presión política sobre la parte demandada y puede ejercer influencia sobre el demandante al momento de elegir el foro que utilice. Sin embargo, el aspecto negativo de contar con mayor cantidad de partes es que puede resultar más difícil llegar a una negociación para una solución amigable. En contraste, en el marco del TLCAN solo resulta imprescindible extender el arreglo amistoso a una tercera parte" (Piérola Castro, 2002, p. 202).

14. En el nuevo sistema el Organismo de Apelación también ha recurrido reiteradamente a la Convención de Viena en tanto expresión de "las normas usuales de interpretación (customary rules of interpretation) del Derecho internacional público". [...] El sistema de solución de diferencias de la O.M.C. ha recurrido, además, de un modo creciente a diversas fuentes del Derecho internacional general: costumbre, doctrina de los publicistas, principios generales del Derecho y otros instrumentos internacionales, en especial los incorporados por referencia en el acuerdo de la O.M.C. y sus acuerdos complementarios (Dupuy, 1999, pp. 269-270; Juste Ruiz, 2003, pp. 398-401; Casanovas y La Rosa, 1998, p. 249). 
Sin embargo, la correcta aplicación del derecho dependerá del grado de conocimiento y de la vinculación que tenga el foro elegido con el instrumento jurídico o las reglas de derecho invocadas.

Se debe resaltar que la elección del foro está indisolublemente ligada a la determinación del derecho aplicable, lo que en ciertas circunstancias no hará posible una elección, pues un foro tendrá competencia exclusiva para cuestiones determinadas que no podrán ser llevadas ante otra jurisdicción. Para poder elegir entre dos o más foros, será necesario que en todos ellos exista un derecho aplicable a la controversia y que pueda atribuírseles competencia para conocer el asunto litigioso ${ }^{15}$. La elección del foro no está únicamente librada a la elección de las partes, sino que dependerá de la materia de la controversia y del derecho aplicable.

\section{CONCLUSIONES}

El sistema que establecen los TLC para la solución de controversias entre Estados no puede ser clasificado como estrictamente jurisdiccional, por cuanto sus pronunciamientos carecen de un efecto definitivo y de la autoridad de cosa juzgada.

Asimismo, el hecho de que el informe final contenga determinaciones y recomendaciones y el margen de discrecionalidad de que gozan las partes para darle cumplimiento hacen que el panel o grupo arbitral no sea idéntico al arbitraje interestatal, y que el informe final no tenga las mismas características que el laudo. En realidad, las atribuciones del panel o grupo arbitral toman elementos del arbitraje, pero también de la conciliación, en una fórmula híbrida que trata de mantener la ductilidad necesaria para permitir un arreglo directo entre las partes, guiadas por las conclusiones del informe final, pero dejando abierto un espacio a la negociación respecto a cuándo y cómo cumplir las obligaciones o a la eliminación de la medida o acto que causó anulación o menoscabo.

Finalmente, el hecho de que las partes ejerzan siempre un control directo sobre las medidas de retaliación, pero no una libre disposición de las mismas, hace que el procedimiento de solución de controversias se convierta en la viga maestra sobre la cual reposa el cumplimiento de las obligaciones emanadas de los TLC, procurando una situación de equilibrio en las facultades de las partes para lograr sus objetivos y darle al convenio un efecto útil y provechoso, en el contexto del libre intercambio deseado.

\section{REFERENCIAS}

Casanovas y La Rosa, O. (1998). Unidad y pluralismo en derecho internacional público. En Cursos Euromediterráneos Bancaja de Derecho Internacional (vol. II).

Centro de Comercio Internacional UNCTAD/OMC y Commonwealth Secretariat. (1996). Guía de la Ronda Uruguay para la Comunidad Empresarial. Ginebra: Autor.

Diez de Velasco, M. (2003). Instituciones de derecho internacional público (14. ${ }^{a}$ ed.). Madrid: Tecnos

Dupuy, P-M. (1999). Multiplication des juridictions internationales et dangers de fragmentation de l'ordre juridique international. En Cursos Euromediterráneos Bancaja de Derecho Internacional (vol. III).

Juste Ruiz, K. (2003). Protección del medio ambiente y comercio internacional. En Cursos Euromediterráneos Bancaja de Derecho Internacional (vol. VII).

Montañá Mora, M. (1997). La OMC y el reforzamiento del sistema GATT. Madrid: McGraw-Hill.

Novak Talavera, F. \& García-Corrochano Moyano, L. (2005). Solución pacífica de controversias. En Derecho internacional público (tomo III). Lima: Pontificia Universidad Católica del Perú.

Piérola Castro, F. (2002). Solución de diferencias en la Organización Mundial del Comercio. Lima: Pontificia Universidad Católica del Perú.

Rodríguez Carrión, A. (2006). Lecciones de derecho internacional público (6. ${ }^{\mathrm{a}}$ ed.). Madrid: Tecnos.

Tratado de Libre Comercio de América del Norte (1992). Whashington D.C., Estados Unidos.

Tratado de Libre comercio Estados Unidos - Chile. (2003). Miami, Florida, Estados Unidos.

Tratado de Libre comercio Estados Unidos - Perú. (2006). Whashington D.C., Estados Unidos.

World Trade Organization. (1995). The Results of the Uruguay Round of Multilateral Trade Negotiations, the Legal Texts. Geneva: Autor.

15. “Evidentemente, la elección del foro más adecuado es solo factible si existen disposiciones que regulan las mismas materias en uno y otro ámbito normativo. Si por el contrario, un ordenamiento regula aspectos que el otro no, no debiera existir competencia. Así por ejemplo, dado que el TLCAN regula algunas materias relativas a competencia que no se encuentran bajo el alcance de los Acuerdos OMC, el TLCAN es el único sistema con competencia jurisdiccional para conocer de dichos asuntos" (Piérola Castro, 2002, p. 202). 